\title{
Hierarchically assembled helicates as reaction platform - from stoichiometric Diels-Alder reactions to enamine catalysis
}

\author{
David Van Craen, Jenny Begall, Johannes Großkurth, Leonard Himmel, \\ Oliver Linnenberg, Elisabeth Isaak and Markus Albrecht ${ }^{*}$
}

Open Access

\author{
Full Research Paper \\ Address: \\ Institute of Organic Chemistry, RWTH Aachen University, Landoltweg \\ 1, 52074 Aachen, Germany \\ Email: \\ Markus Albrecht ${ }^{*}$ - markus.albrecht@oc.rwth-aachen.de \\ * Corresponding author \\ Keywords: \\ Diels-Alder reaction; enamine catalysis; hierarchical helicates; \\ remote-control; stereoselectivity
}

Beilstein J. Org. Chem. 2020, 16, 2338-2345.

https://doi.org/10.3762/bjoc.16.195

Received: 17 July 2020

Accepted: 10 September 2020

Published: 24 September 2020

This article is part of the thematic issue "Molecular recognition" and is dedicated to the memory of Carsten Schmuck.

Guest Editor: J. Niemeyer

(C) 2020 Van Craen et al.; licensee Beilstein-Institut.

License and terms: see end of document.

\section{Abstract}

The stereoselectivity of a Diels-Alder reaction within the periphery of hierarchically assembled titanium(IV) helicates formed from mixtures of achiral, reactive and chiral, unreactive ligands was investigated in detail. Following the pathway of the chiral induction, the chiral ligands, solvents as well as substituents at the dienophile were carefully varied. Based on the results of the stoichiometric reaction, a secondary amine-catalyzed nitro-Michael reaction is performed as well which afforded reasonable diastereoselectivities.

\section{Introduction}

Carbon-carbon $(\mathrm{C}-\mathrm{C})$ bond-forming reactions play a key role in organic chemistry. Hereby the stereoselectivity of the reaction is highly important due to the different behavior of stereoisomers in human metabolism [1,2]. Stereocontrol was achieved either via an auxiliary [3-7] or a catalyst [8], both providing the stereoinformation necessary for induction during the $\mathrm{C}-\mathrm{C}$ bond formation. Catalytic approaches for $\mathrm{C}-\mathrm{C}$ bond-forming reactions even found their way into the relatively young field of supramolecular chemistry, e.g., regioselective Diels-Alder reactions within supramolecular hosts as described by Fujita et al. [9-11] or stereoselective nucleophilic substitutions by Raymond et al. [12] are important examples in this context. Recently, we described the use of hierarchically assembled helicates as templates for stereoselective Diels-Alder reactions via a post-functionalization process [13]. Catechol ligands $\mathbf{L}-\mathbf{H}_{2}$ with an ester functionality in the 3-position were prepared via conversion of the acid chloride of 2,3-dihydroxybenzoic acid to the corresponding esters. These ligands underwent a complexation with titanoyl(IV) bisacetylacetonate and lithium carbonate initially forming a mononuclear "Werner-type" triscatecholate titanium(IV) complex. Two of these monomers dimerized in a consecutive step to obtain a non-covalently linked helicate 
(Scheme 1). The dimerization took place via the coordination of three lithium cations acting as bridges between two monomeric complex units [13-20].

Enantioselectivities up to $25 \%$ ee at elevated temperature $\left(32 \%\right.$ ee at $\left.0{ }^{\circ} \mathrm{C}\right)$ depending on the substrate were achieved in a Diels-Alder reaction by introducing two different substituted catechol ester ligands during the complex formation: (1) A diene-substituted ligand $\mathbf{1}-\mathbf{H}_{2}$ for the Diels-Alder reaction $[21,22]$ and (2) a chiral ligand $\mathbf{2}-\mathbf{H}_{\mathbf{2}}$ for the stereocontrol [13]. Cleaving the complex under acidic conditions resulted in the desired enantiomerically enriched product 9 and enabled the recovery of the chiral ligand $\mathbf{2}-\mathbf{H}_{\mathbf{2}}$ (Scheme 2) [13].

The solvent choice allowed on/off-switching of the stereoselectivity of the Diels-Alder reaction. In THF the stereochemically locked dimer of the hierarchical helicate was present. Here stereoselectivity was turned on. On the other hand, the highly dynamic and fast diastereomerizing/epimerizing monomer was the major species in DMF switching off the stereoselectivity [13].

Herein we investigated the induction pathway and significantly optimized the stereoselectivity of the reaction. Furthermore, a catalytic approach was introduced which paves the way to the final goal of supramolecular stereoselective catalysis with hierarchical helicates as homogeneous catalysts.

\section{Results and Discussion Stereoselective Diels-Alder reactions in the periphery of hierarchically assembled helicates}

Elucidating the induction pathway of the Diels-Alder reaction is vital for the optimization of the system described above and for the development of future processes based on the principle<smiles>O=C(O)c1cccc(O)c1O</smiles>
1.) $\mathrm{SOCl}_{2}$
2.) $\mathrm{ROH}, \mathrm{NEt}_{3}$,
$\mathrm{CHCl}_{3}$<smiles>[R]C(=O)c1cccc(O)c1O</smiles>

L- $\mathrm{H}_{2}$

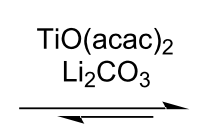

$2 \mathrm{Li}_{2}$

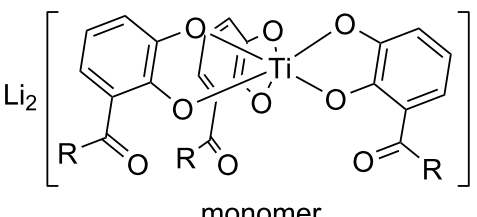

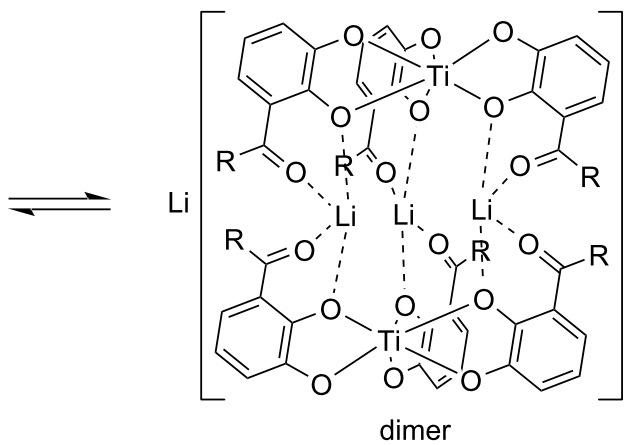<smiles>C/C=C/C=C/CO</smiles>

4- $\mathrm{H}_{2}$<smiles>CCOC(C)c1ccccc1</smiles>

$5-\mathrm{H}_{2}$<smiles>CC(O)c1ccc2ccccc2c1</smiles>

6- $\mathrm{H}_{2}$

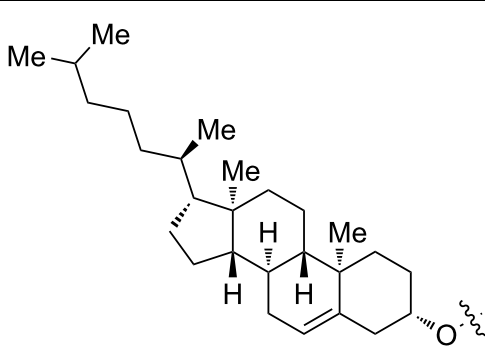

7- ${ }_{2}$ 


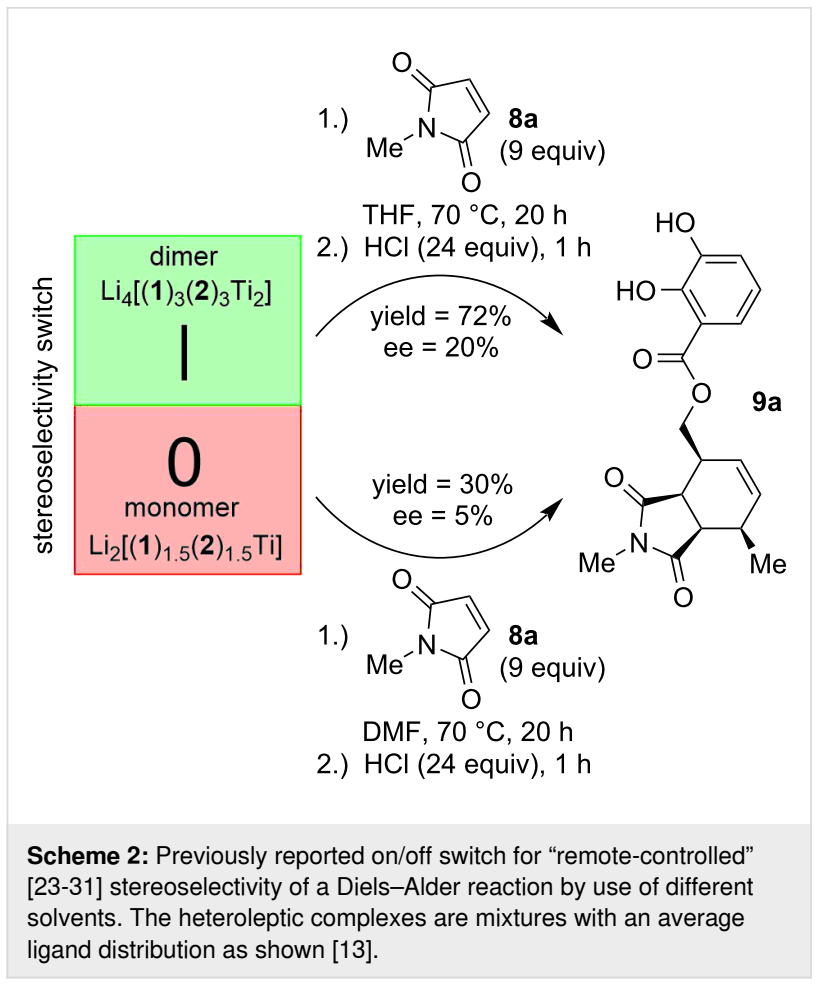

to use self-assembled coordination platforms (or as in the present case mixtures thereof) to control stereoselective $\mathrm{C}-\mathrm{C}$ bond-forming reactions. Stereoinduction usually relies on spatial proximity of the prochiral carbon atoms and a chiral information of, e.g., a chiral auxiliary, Lewis acid or catalyst. In the previously reported system two different induction pathways were conceivable: (1) A chiral ligand is located close to the diene and controls the stereochemistry of the cycloaddition. (2) The chiral ligand controls the helicity of the helicate $(\Delta \Delta$ or $\Lambda \Lambda)$ and the helix induces the stereoselectivity of the Diels-Alder reaction.

To find out which of the induction pathways takes over the control of the Diels-Alder reaction in the periphery of the helicates, a specific helicity was induced at an achiral diene bearing helicate. It has been described before that an addition of chiral ammonium salts leads to the preference of a specific twist at the helicate [32]. As inductor, $(R)$-1-phenylethylammonium chloride was added to the racemic hexadiene-substituted helicate $\left[\mathrm{Li}_{3}(\mathbf{1})_{6} \mathrm{Ti}_{2}\right]^{-}$. The chiral salt influences the helicity of the monomeric complexes and which dimerize to the right-handed $(\Delta \Delta)$ helicate [32]. As the process is slow, the mixture of the ammonium salt and complex was stirred for two weeks at room temperature in methanol. Thereafter, the solvent was removed and the Diels-Alder reaction with $N$-benzylmaleimide was performed at elevated temperature in THF. The reaction yielded the racemic product after purification. Scheme 3 is showing that the induction of stereochemistry of the Diels-Alder reaction depends on the chirality at the chiral ligand and not at the helix. This allows improvement of the stereoselectivity by using more appropriate sterically hindered or rigid chiral ligands. In addi-

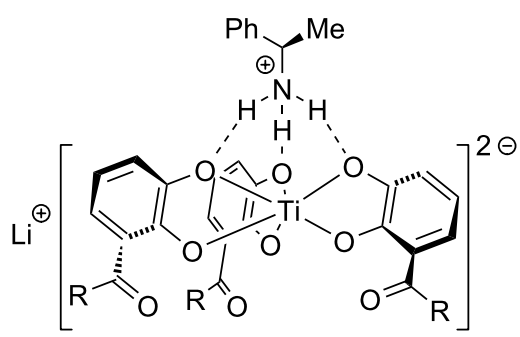

$\mathrm{XLi}\left[(\mathbf{1})_{3} \mathrm{Ti}\right], \Delta$ monomer favored

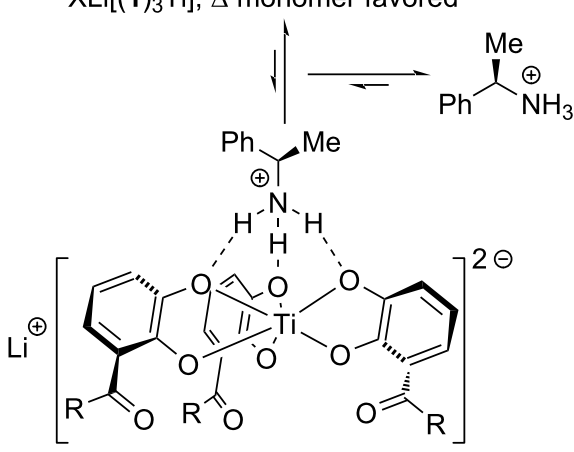

$\mathrm{XLi}\left[(\mathbf{1})_{3} \mathrm{Ti}\right], \Lambda$ monomer unfavored

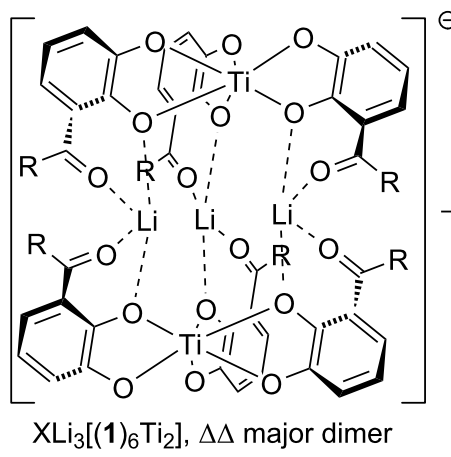<smiles>O=C1C=CC(=O)N1C(=O)c1ccccc1</smiles>
9 equiv, THF, $70{ }^{\circ} \mathrm{C}, 20 \mathrm{~h}$

2.) $\mathrm{HCl}$ (24 equiv), $\mathrm{rt}, 1 \mathrm{~h}$

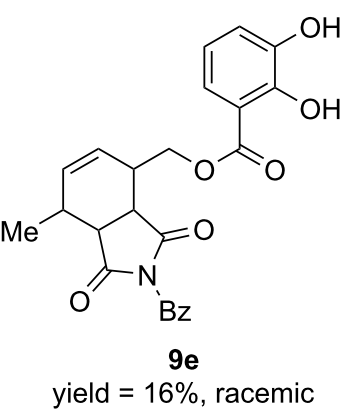

$\mathrm{X}=$ chiral ammonium moiety<smiles>[R]OC/C=C/C</smiles>

Scheme 3: Elucidating the pathway of the stereoinduction of the Diels-Alder reaction. Ten equivalents of chiral ammonium salt are added to the hierarchical helicate in methanol and stirred for two weeks. Afterwards methanol is removed and the residue is dissolved in THF to perform a Diels-Alder reaction at the side chain. 
tion, a solvent screening was performed in which solvents were used which favor the dimer. This is imminent for good enantioselectivities because the presence of a high amount of stereolabile monomer switches off the selectivity [13].

\section{Solvent dependence}

Initially the solvent dependence of the stereochemical induction of the Diels-Alder reaction by the phenylethyl-derived ligand 2 was studied using $N$-benzylmaleimide (8e) as dienophile (Table 1). The solvents dioxane $(17 \%$ ee) and acetone (14\% ee) showed a slight decrease of the enantioselectivity compared to THF ( $21 \%$ ee). The yields of the reactions were rather moderate. On the other hand, the use of acetonitrile had no significant influence on the yield compared to acetone while the enantioselectivity dramatically dropped to $8 \%$ ee. In this case the lower selectivity correlated with the increasing lithium solvating capability of the solvent resulting in a higher proportion of the monomer and thus in lower stereoselectivities. In contrast to this, less polar solvents such as dichloromethane and chloroform resulted in increasing stereoselectivities in the
Diels-Alder reaction due to their poor ability to stabilize lithium cations. Chloroform showed the best induction with $32 \%$ ee followed by dichloromethane with $25 \%$ ee, both with $50 \%$ yield (Table 1).

\section{Ligand screening}

In a second optimization step, the chiral ligands have been varied. An increase of stereoselectivity was achieved by using the helicates with a statistical ligand distribution $\mathrm{Li}\left[\mathrm{Li}_{3}(\mathbf{1})_{3}\left(\mathbf{L}^{*}\right)_{3} \mathrm{Ti}_{2}\right]\left(\mathrm{L}^{*}=\mathbf{3}-\mathbf{7}-\mathrm{H}_{2}\right)$. The given formula only describes the ratio of the ligands but in fact a statistical mixture of complexes $\operatorname{Li}\left[\mathrm{Li}_{3}\left(\mathbf{L}^{*}\right)_{6} \mathrm{Ti}_{2}\right], \quad \operatorname{Li}\left[\mathrm{Li}_{3}(\mathbf{1})(\mathbf{L} *)_{5} \mathrm{Ti}_{2}\right]$, $\mathrm{Li}\left[\operatorname{Li}_{3}(\mathbf{1})_{2}\left(\mathbf{L}^{*}\right)_{4} \mathrm{Ti}_{2}\right], \operatorname{Li}\left[\mathrm{Li}_{3}(\mathbf{1})_{3}\left(\mathbf{L}^{*}\right)_{3} \mathrm{Ti}_{2}\right], \mathrm{Li}\left[\mathrm{Li}_{3}(\mathbf{1})_{4}\left(\mathbf{L}^{*}\right)_{2} \mathrm{Ti}_{2}\right]$, $\mathrm{Li}\left[\mathrm{Li}_{3}(\mathbf{1})_{5}\left(\mathbf{L}^{*}\right)_{1} \mathrm{Ti}_{2}\right]$, and $\mathrm{Li}\left[\mathrm{Li}_{3}(\mathbf{1})_{6} \mathrm{Ti}_{2}\right]$ is present. Expanding the aromatic unit to a naphthyl group in $\mathbf{3}-\mathbf{H}_{2}$ resulted in an increase of the enantioselectivity to $44 \%$ ee. Even better selectivities were obtained with $\mathbf{4}-\mathbf{H}_{\mathbf{2}}$ bearing an indanyl $[33,34]$ substituent which combines a stereogenic center implemented in a ring system providing rigidity as well as an aromatic residue. The enantioselectivity increased to $58 \%$ ee (Table 1 ).

Table 1: Optimization of the stereoselectivity achieved of the Diels-Alder reaction at hierarchical helicates with solvent and chiral ligand screening.<smiles>[R]N1C(=O)C2C(C)C=CC(COC(=O)c3cccc(O)c3O)C2C1=O</smiles>

\begin{tabular}{|c|c|c|c|c|c|c|c|}
\hline Entry & $\mathbf{L}^{*}$ & 9 & $\mathrm{R}$ & solvent & $\begin{array}{l}T \\
{\left[{ }^{\circ} \mathrm{C}\right]}\end{array}$ & $\begin{array}{l}\text { yield } \\
{[\%]}\end{array}$ & $\begin{array}{l}\mathrm{ee} \\
{[\%]}\end{array}$ \\
\hline 1 & 2 & e & $\mathrm{Bz}$ & THF & 70 & 77 [13] & 21 [13] \\
\hline 2 & 2 & e & $\mathrm{Bz}$ & dioxane & 105 & 53 & 17 \\
\hline 3 & 2 & e & $\mathrm{Bz}$ & acetone & 60 & 50 & 14 \\
\hline 4 & 2 & e & $\mathrm{Bz}$ & $\mathrm{MeCN}$ & 86 & 44 & 8 \\
\hline 5 & 2 & e & $\mathrm{Bz}$ & $\mathrm{DCM}$ & 44 & 50 & 25 \\
\hline 6 & 2 & e & $\mathrm{Bz}$ & $\mathrm{CHCl}_{3}$ & 65 & 50 & 32 \\
\hline 7 & 3 & e & $\mathrm{Bz}$ & $\mathrm{CHCl}_{3}$ & 65 & 71 & 44 \\
\hline 8 & 4 & e & $\mathrm{Bz}$ & $\mathrm{CHCl}_{3}$ & 65 & 64 & 58 \\
\hline 9 & 5 & e & $\mathrm{Bz}$ & $\mathrm{CHCl}_{3}$ & 65 & 61 & 46 \\
\hline 10 & 6 & e & $\mathrm{Bz}$ & $\mathrm{CHCl}_{3}$ & 65 & 64 & 16 \\
\hline 11 & 7 & e & $\mathrm{Bz}$ & $\mathrm{CHCl}_{3}$ & 65 & 11 & -8 \\
\hline 12 & 4 & a & $\mathrm{Me}$ & $\mathrm{CHCl}_{3}$ & 65 & 76 & 43 \\
\hline 13 & 4 & b & Et & $\mathrm{CHCl}_{3}$ & 65 & 79 & 39 \\
\hline 14 & 4 & c & $t$-Bu & $\mathrm{CHCl}_{3}$ & 65 & 82 & 18 \\
\hline 15 & 4 & d & Cy & $\mathrm{CHCl}_{3}$ & 65 & 80 & 49 \\
\hline
\end{tabular}

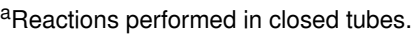


Besides the aromatic ligands, terpenyl-substituted ligands were investigated, too. The largest ligand $\mathbf{7}-\mathbf{H}_{\mathbf{2}}$ with a cholesteryl moiety favored the opposite enantiomer, however, only with $-8 \%$ ee in only $11 \%$ yield. The low yield may be attributed to the poor solubility of the helicate. The other terpene $[35,36]$ derived systems $\operatorname{Li}\left[\operatorname{Li}_{3}(\mathbf{1})_{3}(\mathbf{5})_{3} \mathrm{Ti}_{2}\right]$ and $\operatorname{Li}\left[\mathrm{Li}_{3}(\mathbf{1})_{3}(\mathbf{6})_{3} \mathrm{Ti}_{2}\right]$ showed a different behavior. The $(1 S, 2 S, 3 S, 5 R)$-3-pinanylsubstituted $\mathrm{Li}\left[\mathrm{Li}_{3}(\mathbf{1})_{3}(\mathbf{5})_{3} \mathrm{Ti}_{2}\right]$ yielded $46 \%$ ee, while the complex bearing a L-(-)-borneyl residue $\mathrm{Li}_{[}\left[\mathrm{Li}_{3}(\mathbf{1})_{3}(\mathbf{6})_{3} \mathrm{Ti}_{2}\right]$ showed only $16 \%$ ee. The yields were higher than $60 \%$. A possible reason for the significant drop in enantioselectivity by switching from ligand $\mathbf{5}$ to $\mathbf{6}$ was due to the different dimerization behavior. The homoleptic helicate $\operatorname{Li}\left[\operatorname{Li}_{3}(6)_{6} \mathrm{Ti}_{2}\right]$ shows a lower dimerization tendency compared to $\operatorname{Li}\left[\mathrm{Li}_{3}(\mathbf{5})_{6} \mathrm{Ti}_{2}\right][35,36]$. Thus, the higher amount of undesired monomer in solution of $\mathrm{Li}\left[\mathrm{Li}_{3}(\mathbf{1})_{3}(\mathbf{6})_{3} \mathrm{Ti}_{2}\right]$ resulted in a partial switch-off of the stereoselectivity.

\section{Screening of the dienophile}

The variation of the dienophile was studied in chloroform using the helicate $\mathrm{Li}_{4}\left[(\mathbf{1})_{3}(\mathbf{4})_{3} \mathrm{Ti}_{2}\right] . N$-Maleimides $\mathbf{8 a}$ and $\mathbf{8 b}$ with a methyl and an ethyl residue showed higher yields and a lower induction in comparison to the benzyl derivative $\mathbf{8 e}$ with $43 \%$ ee and $39 \%$ ee (Table 1 ). The poorest result was obtained by using dienophile $\mathbf{8 c}$ with a tert-butyl substituent ( $82 \%$ yield, $18 \%$ ee). This maleimide gave the lowest induction in our previous work, too [13]. Thus, no improvement was made in comparison to the $15 \%$ ee [13] achieved with chiral ligand $\mathbf{2}-\mathbf{H}_{\mathbf{2}}$ in THF as solvent. The cyclohexyl-substituted dienophile 8d showed a higher induction ( $49 \%$ ee and $80 \%$ yield) than $8 \mathbf{a}$ and $\mathbf{8 b}$, but could not reach the results of $\mathbf{8 e}$. The described optimization of the reaction conditions based on solvent, chiral ligand, and substituent at the dienophile resulted in a nearly threefold increase of the enantioselectivity compared to the earlier described results [13].

The screening showed the opportunity to use hierarchically formed helicates with mixtures of ligands as platforms to control the stereochemistry of $\mathrm{C}-\mathrm{C}$ bond-forming reactions. However, it would be of great advantage to transfer the findings to catalytic $\mathrm{C}-\mathrm{C}$ bond-forming reactions which are catalyzed by hierarchical helicates containing chiral ligands for stereocontrol and achiral catalytically active ligands.

\section{Enamine-catalyzed nitro-Michael reactions}

The nitro-Michael reaction [37-40] seemed to be suitable to be performed at hierarchically assembled helicates due to the reaction's "benchmark character" [41]. Therefore, ligands bearing secondary amine residues were introduced instead of the diene ligands. Again helicates with a statistical distribution of chiral ligands and of the new amine ligands in the complex were in- vestigated as catalysts. The ligands with potential catalytic activity were synthesized in a three-step approach (Scheme 4). Initially the amino alcohols 10a-d were protected with a Boc group [42,43]. Esterification of the protected alcohols 11a-d $[33,44]$ with 2,3-dioxosulfinylbenzoyl chloride obtained from 2,3-dihydroxybenzoic acid and thionyl chloride afforded the $N$-Boc-substituted catechol ligands 12a-d $[33,36]$. They were deprotected under acidic conditions with hydrochloric acid yielding ligands $\mathbf{1 3 a}-\mathbf{d}-\mathbf{H}_{\mathbf{2}}[33,36]$ as ammonium chloride salts.

1.) $\mathrm{Boc}_{2} \mathrm{O}, \mathrm{DCM}$, $0{ }^{\circ} \mathrm{C}$ to $\mathrm{rt}, 1 \mathrm{~d}$

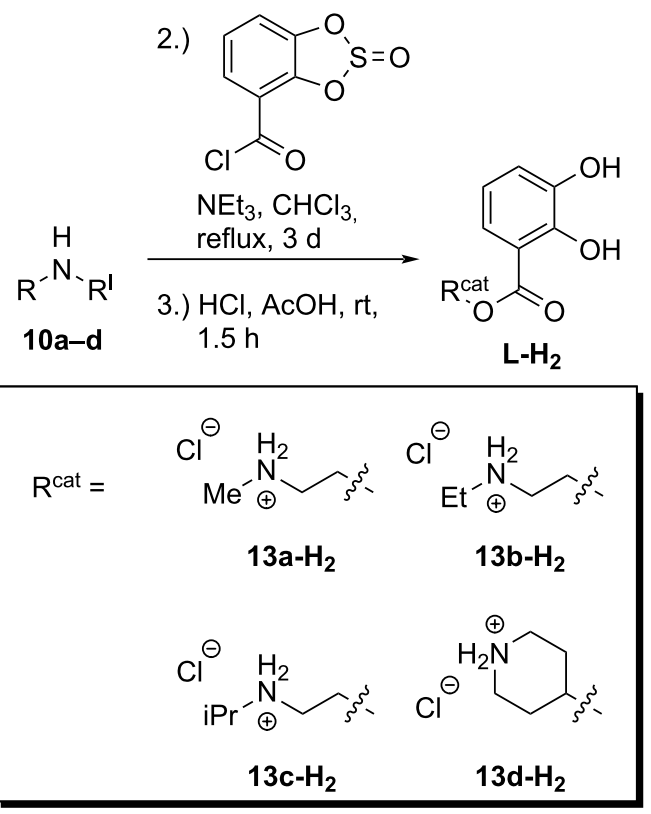

Scheme 4: Synthesis of the ligands with secondary amine-containing substituents.

The obtained ligands 13a-d- $\mathbf{H}_{2}$ were used together with the

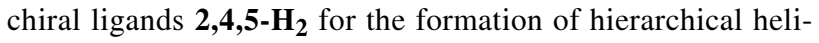
cates with a statistical ligand ratio which were formed from

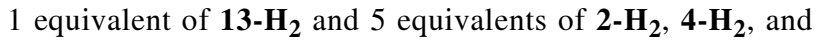
$5-\mathrm{H}_{2}$.

The catalytic activity of the amine ligands was tested first by using the uncoordinated ligand $\mathbf{1 3 a}-\mathbf{H}_{2}$ substituted with a $\mathrm{N}$-methylethylamine moiety. The reaction was performed in DMSO- $d_{6}$ due to solubility limitations of the ligand. Fast and easy measurement of the yield and the diastereoselectivity was possible by NMR spectroscopy. The nitro-Michael reaction of 3 equivalents propanal (14) and $\beta$-nitrostyrene (15) with $25 \mathrm{~mol} \%$ of $\mathbf{1 3} \mathbf{a}-\mathbf{H}_{2}$ after 2 days at room temperature resulted in $45 \%$ yield of product $\mathbf{1 6}$ and a nearly 1:1 diastereomeric ratio (Table 2). 
Table 2: Enamine-catalyzed nitro-Michael reaction with hierarchically assembled helicates. ${ }^{\text {a }}$

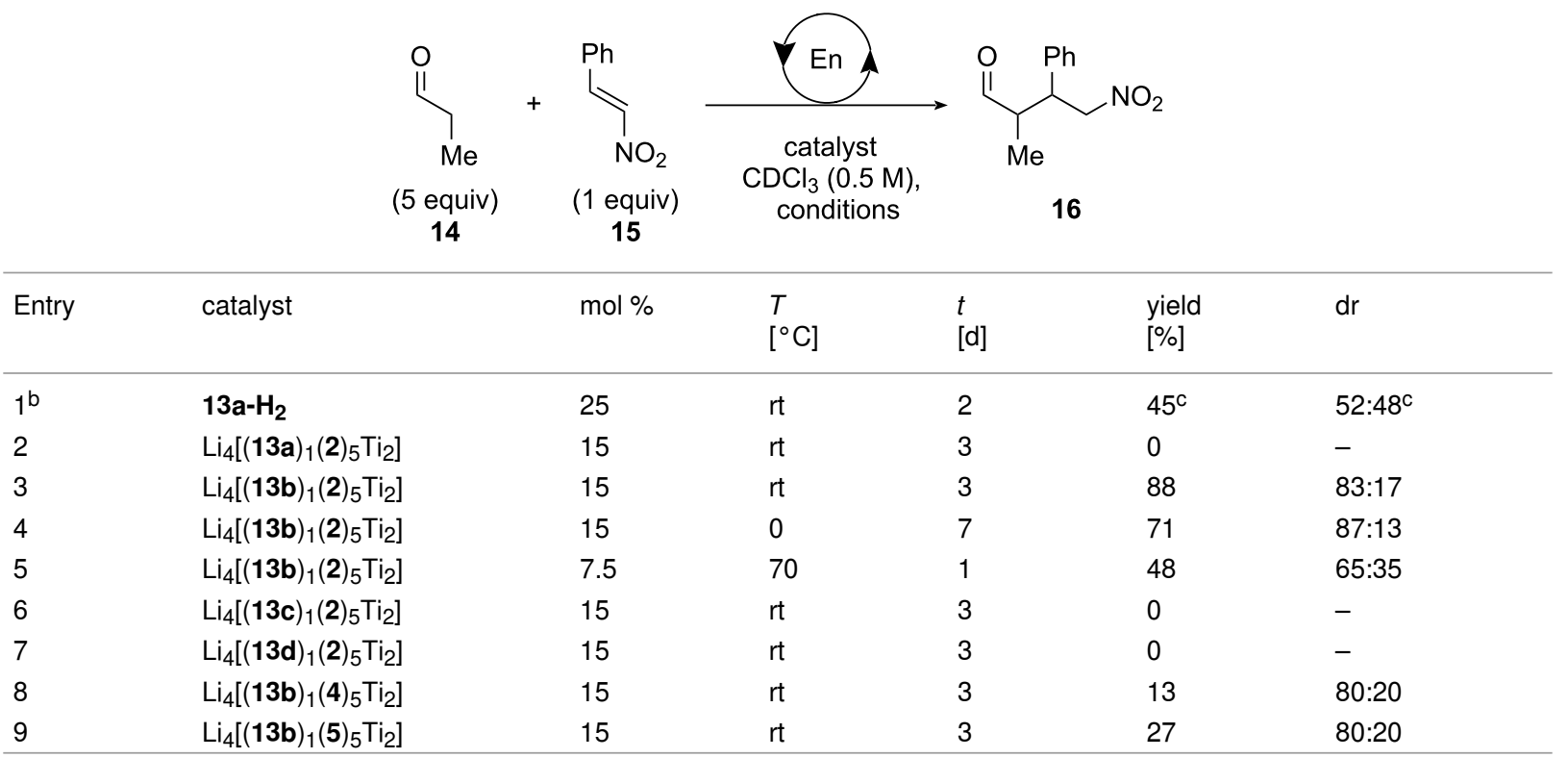

aNo enantioselectivity was achieved. ${ }^{b}$ Reaction was performed in DMSO- $d_{6}(0.26 \mathrm{M})$ due to solubility limitations of the free ligand with 3 equiv of propanal. ' $V$ alues determined by integration of the crude NMR spectrum of the reaction.

Catalysis at the "statistical" helicates was carried out with 5 equivalents of propanal (14) in order to gain a higher conversion. Beside a significant control over the diastereomeric ratio no enantioselectivity was achieved with helicates as catalysts. Catalysts at concentrations of $15 \mathrm{~mol} \%$ were used in $\mathrm{CDCl}_{3}$ at room temperature and $0{ }^{\circ} \mathrm{C}$ with three or seven days of reaction time. The conversion was controlled by NMR spectroscopy and TLC. The helicate $\operatorname{Li}_{4}\left[(\mathbf{1 3 a})_{1}(\mathbf{2})_{5} \mathrm{Ti}_{2}\right]$ did not lead to any conversion at room temperature (Table 2). The catalyst $\mathrm{Li}_{4}\left[(\mathbf{1 3 b})_{1}(\mathbf{2})_{5} \mathrm{Ti}_{2}\right]$ with an ethyl-substituted amine worked well resulting in $88 \%$ yield and $66 \%$ de at room temperature. The diastereomeric excess increased slightly to a maximum of $74 \%$ de $(\mathrm{dr} 87: 13)$ at $0{ }^{\circ} \mathrm{C}$. A dramatic decrease to $30 \%$ de was observed by lowering the catalyst loading to $7.5 \mathrm{~mol} \%$ while increasing the temperature to $70{ }^{\circ} \mathrm{C}$. No enantioselectivity was observed using the helicate $\operatorname{Li}_{4}\left[(\mathbf{1 3 b})_{1}(\mathbf{2})_{5} \mathrm{Ti}_{2}\right]$ as catalyst. The helicates $\mathrm{Li}_{4}\left[(\mathbf{1 3 c})_{1}(\mathbf{2})_{5} \mathrm{Ti}_{2}\right]$ and $\mathrm{Li}_{4}\left[(\mathbf{1 3 d})_{1}(\mathbf{2})_{5} \mathrm{Ti}_{2}\right]$ with an isopropyl-substituted ethylamine and a cyclic secondary amine ligand as catalytically active unit showed no conversion in the nitro-Michael reaction. Solubility problems were the supposed reason for this observation. Thus, the amine ligand $\mathbf{1 3 b}-\mathbf{H}_{2}$ seemed to be an appropriate component to make helicates from ligand mixtures which possess catalytic activity.

Exchange of the chiral ligand 2 by other chiral ones resulted in the corresponding complexes $\mathrm{Li}_{4}\left[(\mathbf{1 3 b})_{1}(\mathbf{4})_{5} \mathrm{Ti}_{2}\right]$ and $\mathrm{Li}_{4}\left[(\mathbf{1 3 b})_{1}(\mathbf{5})_{5} \mathrm{Ti}_{2}\right]$, but did not lead to a control of enantioselec- tivity. A reasonable diastereoselectivity of $60 \%$ de was observed for both catalysts. The limited solubility of these complexes caused a significant reduction of the yield at room temperature and due to this the reaction was not performed at lower temperatures.

\section{Conclusion}

An optimization of the Diels-Alder reaction taking place in the periphery of hierarchically assembled helicates was carried out. It was based on the elucidated induction pathway showing that the stereoselectivity was due to the proximity of the chiral units of ligand $\mathbf{2}$ to the diene unit. The helicity of the helicate did not have a significant influence. After optimization of solvent, chiral ligand, and substituent at the dienophile stereoselectivity was nearly tripled. Up to $58 \%$ ee was achieved in the Diels-Alder reaction in chloroform with the indanyl-substituted chiral ligand $\mathbf{4 - \mathbf { H } _ { 2 }}$ and $N$-benzylmaleimide $(\mathbf{8 e})$ as the dienophile.

In addition, the transition from the stoichiometric Diels-Alder reaction to a catalytic nitro-Michael reaction was described utilizing secondary amine ligands as catalysts. Only amine ligand $\mathbf{1 3 b}-\mathbf{H}_{2}$ seemed suitable in the catalysis with the corresponding statistical helicates. With other complexes solubility problems arose. $\mathrm{Li}_{4}\left[(\mathbf{1 3 b})_{1}(\mathbf{2})_{5} \mathrm{Ti}_{2}\right]$ was the most efficient catalyst discussed in this study and provided good yields of up to $88 \%$ at room temperature. Suitable diastereoselectivities were 
obtained with up to $74 \%$ de $(\mathrm{dr} 87: 13)$ at $0{ }^{\circ} \mathrm{C}$ and $66 \%$ de $(\mathrm{dr}$ $83: 17)$ at room temperature. Enantioselectivity was not achieved even with the chiral ligands $\mathbf{4 - \mathbf { H } _ { 2 }}$ and $\mathbf{5}-\mathbf{H}_{2}$.

Nevertheless, the successful implementation of diastereoselective catalysis by hierarchically assembled helicates was a big step forward and will draw our focus on the development of new systems possessing catalytic activity with improved solubility.

\section{Supporting Information}

\section{Supporting Information File 1}

Synthetic procedures, characterization data, SFC and HPLC conditions and copies of ${ }^{1} \mathrm{H}$ and ${ }^{13} \mathrm{C}$ NMR spectra of new compounds.

[https://www.beilstein-journals.org/bjoc/content/ supplementary/1860-5397-16-195-S1.pdf]

\section{Acknowledgements}

We sincerely thank Prof. Magnus Rüping, Cornelia Vermeeren, Prof. Carsten Bolm and Marcus Frings for the determination of the enantio- and diastereoselectivities via SFC and HPLC. Parts of this publication have been published in the Ph.D. thesis [33] of Dr. David Van Craen.

\section{Funding}

Support by the international graduate school SeleCa - Selectivity in Chemo- and Biocatalysis of the DFG (Deutsche Forschungsgemeinschaft) is gratefully acknowledged.

\section{ORCID ${ }^{\circledR}$ iDs}

David Van Craen - https://orcid.org/0000-0002-0501-2233 Johannes Großkurth - https://orcid.org/0000-0001-6525-2872 Markus Albrecht - https://orcid.org/0000-0002-3501-1477

\section{Preprint}

A non-peer-reviewed version of this article has been previously published as a preprint: https://doi.org/10.3762/bxiv.2020.82.v1

\section{References}

1. Clayden, J.; Greeves, N.; Warren, S. Organic Chemistry, 2nd ed.; Oxford University Press: Oxford, U.K., 2012.

2. Brookes, J. C.; Horsfield, A. P.; Stoneham, A. M. J. R. Soc., Interface 2009, 6, 75-86. doi:10.1098/rsif.2008.0165

3. Corey, E. J.; Ensley, H. E. J. Am. Chem. Soc. 1975, 97, 6908-6909. doi:10.1021/ja00856a074

4. Enders, D.; Eichenauer, H. Angew. Chem. 1976, 88, 579-581. doi:10.1002/ange.19760881710
5. Evans, D. A.; Bartroli, J.; Shih, T. L. J. Am. Chem. Soc. 1981, 103, 2127-2129. doi:10.1021/ja00398a058

6. Roos, G., Ed. Key Chiral Auxiliary Applications, 2nd ed.; Academic Press: Boston, MA, USA, 2014. doi:10.1016/c2011-1-05800-9

7. Gnas, Y.; Glorius, F. Synthesis 2006, 1899-1930. doi:10.1055/s-2006-942399

8. Mikami, K.; Lautens, M., Eds. New frontiers in asymmetric catalysis; John Wiley \& Sons: Hoboken, NJ, USA, 2007.

9. Yoshizawa, M.; Tamura, M.; Fujita, M. Science 2006, 312, 251-254. doi:10.1126/science.1124985

10. Wiester, M. J.; Ulmann, P. A.; Mirkin, C. A. Angew. Chem., Int. Ed. 2011, 50, 114-137. doi:10.1002/anie.201000380

11. Fang, Y.; Powell, J. A.; Li, E.; Wang, Q.; Perry, Z.; Kirchon, A.; Yang, X.; Xiao, Z.; Zhu, C.; Zhang, L.; Huang, F.; Zhou, H.-C. Chem. Soc. Rev. 2019, 48, 4707-4730. doi:10.1039/c9cs00091g

12. Zhao, C.; Toste, F. D.; Raymond, K. N.; Bergman, R. G. J. Am. Chem. Soc. 2014, 136, 14409-14412. doi:10.1021/ja508799p

13. Van Craen, D.; Albrecht, M.; Raabe, G.; Pan, F.; Rissanen, K. Chem. - Eur. J. 2016, 22, 3255-3258. doi:10.1002/chem.201600158

14. Albrecht, M.; Mirtschin, S.; de Groot, M.; Janser, I.; Runsink, J.; Raabe, G.; Kogej, M.; Schalley, C. A.; Fröhlich, R. J. Am. Chem. Soc. 2005, 127, 10371-10387. doi:10.1021/ja052326j

15. Albrecht, M.; Baumert, M.; Klankermayer, J.; Kogej, M.; Schalley, C. A. Fröhlich, R. Dalton Trans. 2006, 4395-4400. doi:10.1039/b607295j

16. Albrecht, M.; Fiege, M.; Baumert, M.; de Groot, M.; Fröhlich, R.; Russo, L.; Rissanen, K. Eur. J. Inorg. Chem. 2007, 609-616. doi:10.1002/ejic.200600852

17. Baumert, M.; Albrecht, M.; Winkler, H. D. F.; Schalley, C. A. Synthesis 2010, 953-958. doi:10.1055/s-0029-1218684

18. Albrecht, M.; Isaak, E.; Baumert, M.; Gossen, V.; Raabe, G.; Fröhlich, R. Angew. Chem. 2011, 123, 2903-2906. doi:10.1002/ange.201006448 Angew. Chem., Int. Ed. 2011, 50, 2850-2853. doi:10.1002/anie.201006448

19. Van Craen, D.; de Groot, M.; Albrecht, M.; Pan, F.; Rissanen, K. Z. Anorg. Allg. Chem. 2015, 641, 2222-2227. doi:10.1002/zaac.201500543

20. Van Craen, D.; Rath, W. H.; Huth, M.; Kemp, L.; Räuber, C.; Wollschläger, J. M.; Schalley, C. A.; Valkonen, A.; Rissanen, K.; Albrecht, M. J. Am. Chem. Soc. 2017, 139, 16959-16966. doi:10.1021/jacs.7b10098

21. Chakrabarty, R.; Stang, P. J. J. Am. Chem. Soc. 2012, 134, 14738-14741. doi:10.1021/ja3070073

22. Wang, M.; Lan, W.-J.; Zheng, Y.-R.; Cook, T. R.; White, H. S.; Stang, P. J. J. Am. Chem. Soc. 2011, 133, 10752-10755. doi:10.1021/ja204155r

23. van Leeuwen, P. W. N. M.; Rivillo, D.; Raynal, M.; Freixa, Z J. Am. Chem. Soc. 2011, 133, 18562-18565. doi:10.1021/ja207912d

24. Ohmatsu, K.; Ito, M.; Kunieda, T.; Ooi, T. Nat. Chem. 2012, 4, 473-477. doi:10.1038/nchem.1311

25. Ohmatsu, K.; Hara, Y.; Ooi, T. Chem. Sci. 2014, 5, 3645-3650. doi:10.1039/c4sc01032a

26. Kokan, Z.; Glasovac, Z.; Majerić Elenkov, M.; Gredičak, M.; Jerić, I.; Kirin, S. I. Organometallics 2014, 33, 4005-4015. doi:10.1021/om5005385

27. Zwick, B. D.; Arif, A. M.; Patton, A. T.; Gladysz, J. A. Angew. Chem. 1987, 99, 921-922. doi:10.1002/ange.19870990914

28. Dydio, P.; Dzik, W. I.; Lutz, M.; de Bruin, B.; Reek, J. N. H. Angew. Chem., Int. Ed. 2011, 50, 396-400. doi:10.1002/anie.201005173 
29. Liao, S.; Sun, X.-L.; Tang, Y. Acc. Chem. Res. 2014, 47, 2260-2272. doi:10.1021/ar800104y

30. Wieland, J.; Breit, B. Nat. Chem. 2010, 2, 832-837. doi:10.1038/nchem. 800

31. Gianneschi, N. C.; Bertin, P. A.; Nguyen, S. T.; Mirkin, C. A.; Zakharov, L. N.; Rheingold, A. L. J. Am. Chem. Soc. 2003, 125, 10508-10509. doi:10.1021/ja035621h

32. Albrecht, M.; Isaak, E.; Moha, V.; Raabe, G.; Fröhlich, R. Chem. - Eur. J. 2014, 20, 6650-6658. doi:10.1002/chem.201402370

33. Van Craen, D. Hierarchisch gebildete Helicate als Plattform für stereoselektive Reaktionen und Katalyse. Ph.D. Thesis, RWTH Aachen University,, Aachen, Germany, 2017.

34. Teitelbaum, A. M.; Meissner, A.; Harding, R. A.; Wong, C. A.; Aldrich, C. C.; Remmel, R. P. Bioorg. Med. Chem. 2013, 21 , 5605-5617. doi:10.1016/j.bmc.2013.05.024 See for the synthesis of the required $(S)$-1-indany.

35. Albrecht, M.; Isaak, E.; Shigemitsu, H.; Moha, V.; Raabe, G.; Fröhlich, R. Dalton Trans. 2014, 43, 14636-14643. doi:10.1039/c4dt01553c

36. Isaak, E. Stereoselektive hierarchische Selbstorganisation von Helicaten. Ph.D. Thesis, RWTH Aachen University, Aachen, Germany, 2013.

37. Seebach, D.; Goliński, J. Helv. Chim. Acta 1981, 64, 1413-1423. doi:10.1002/hlca.19810640518

38. Blarer, S. J.; Schweizer, W. B.; Seebach, D. Helv. Chim. Acta 1982, 65, 1637-1654. doi:10.1002/hlca.19820650537

39. Hayashi, Y.; Gotoh, H.; Hayashi, T.; Shoji, M. Angew. Chem., Int. Ed. 2005, 44, 4212-4215. doi:10.1002/anie.200500599

40. Bures, J.; Armstrong, A.; Blackmond, D. G. J. Am. Chem. Soc. 2011, 133, 8822-8825. doi:10.1021/ja203660r

41. Burés, J.; Armstrong, A.; Blackmond, D. G. J. Am. Chem. Soc. 2012, 134, 6741-6750. doi:10.1021/ja300415t

42. Krapcho, A. P.; Maresch, M. J.; Lunn, J. Synth. Commun. 1993, 23, 2443-2449. doi:10.1080/00397919308011130

43. Saari, W. S.; Schwering, J. E.; Lyle, P. A.; Smith, S. J.; Engelhardt, E. L. J. Med. Chem. 1990, 33, 97-101. doi:10.1021/jm00163a016

44. Chang, D.; Feiten, H.-J.; Engesser, K.-H.; van Beilen, J. B.; Witholt, B.; Li, Z. Org. Lett. 2002, 4, 1859-1862. doi:10.1021/ol025829s

\section{License and Terms}

This is an Open Access article under the terms of the Creative Commons Attribution License (https://creativecommons.org/licenses/by/4.0). Please note that the reuse, redistribution and reproduction in particular requires that the authors and source are credited.

The license is subject to the Beilstein Journal of Organic Chemistry terms and conditions: (https://www.beilstein-journals.org/bjoc)

The definitive version of this article is the electronic one which can be found at: https://doi.org/10.3762/bjoc.16.195 